\title{
Teoria arquivística: muito barulho por nada
}

\author{
John Roberts \\ National Park Service, National Archive, Washington, DC, USA \\ john roberts54@icloud.com
}

DOI: https://doi.org/10.26512/rici.v12.n2.2019.23016

Recebido/Recibido/Received: 2019-01-10

Aceitado/Aceptado/Accepted: 2019-03-11

Resumo: O campo da teoria arquivística não é tão fértil quanto Frank Burke, Gregg Kimball e outros autores sugerem. A teoria arquivística se divide em duas vertentes; uma vertente arquivística, que não é teórica, que lida com a prática, o "como fazer", representando o básico do trabalho de arquivo; essa é a responsabilidade dos arquivistas "clínicos". A outra é teórica, embora não arquivística, e se relaciona à historiografia; representa um esforço para os arquivistas, não em seu papel de arquivistas, mas como historiadores. Este fato restringe o território para os arquivistas teóricos na sua capacidade de arquivistas teóricos. Além disso, os convites para o desenvolvimento de um corpo teórico da área derivam muito mais de uma necessidade emocional por parte de uma comunidade arquivística buscando maior aceitação profissional do que de uma necessidade objetiva por mais teoria arquivística.

Palavras-chave: Teoria arquivística. Prática arquivística. Arquivologia. Historiografia.

\section{Teoría archivística: mucho ruido y pocas nueces}

Resumen: El cam de la teoría de los archivos no es tan fértil como lo Frank Burke, Gregg Kimball y otros autores sugieren. La teoría de los archivos se divide en dos vertientes. Una vertiente que no es teórica, y se ocupa de los aspectos prácticos y esenciales del trabajo de archivo; Esta es la responsabilidad de los archiveros "clínicos". La otra es teórica pero no archivística, y se ocupa de la historiografía; este es un esfuerzo no para los archiveros como archiveros, sino para los archiveros como historiadores, que restringe el territorio a los archiveros teóricos en su capacidad de archiveros teóricos, además, las invitaciones para desarrollar un cuerpo teorico del área pueden derivar mucho más de una necesidad emocional por parte de una comunidad archivística buscando una mayor aceptación profesional que de una necesidad objetiva por más teoría archivística.

Palabras clave: Teoría archivística. Práctica archivística. Archivística. Historiografía.

\section{Archival Theory: much ado about shelving}

Abstract: The field of archival theory is not as fertile as Frank Burke, Gregg Kimball, and others suggest. There are two strains to archival theory. One strain is archival but not theoretical, and deals with the practical, how-to, nitty-gritty of archival work; this is the responsibility of archival clinicians. The other is theoretical but not archival and is concerned with historiography; this is an endeavor not for archivists as archivists but for archivists as historians. This leaves very restricted territory indeed for the archival theorist qua archival theorist. Moreover, the calls for developing a body of archival theory may derive less from an objective need for more archival theory than from an emotional need on the part of an archival community seeking greater professional acceptance.

Key words: Archival theory. Record management. Archival Science. Historiography

Sobre o autor: Aposentou-se como arquivista sênior do National Park Service. Teve a função de arquivista do National Archive dos Estados Unidos. Possui doutorado em História dos Estados Unidos pela University of Maryland, MD. 
Sobre o título: "Muito Barulho para Nada": Expressão que ficou conhecida por conta da comédia de William Shakespeare, Much Ado About Nothing, traduzida para o português como Muito barulho por nada.

Sobre o artigo: Artigo publicado originalmente como: ROBERTS, John. Archival theory: much ado about shelving. American Archivist, v. 50, p. 66-74, 1987. Disponível em: www.americanarchivist.org/doi/pdf/10.17723/aarc.50.1.1357257455776g52

Agradecemos ao autor e ao editor da revista, pela autorização da tradução e publicação na $\mathrm{RICl}$. Traduzido para o português por Shirley Carvalhêdo Franco, com revisão técnica de Cynthia Roncaglio, respectivamente membro e líder do Grupo de Pesquisa Fundamentos Históricos, Epistemológicos e Teóricos da Arquivologia - GP FHETA, certificado pelo Diretório de Grupos de Pesquisa do CNPq, vinculado ao Programa de Pós-Graduação em Ciência da Informação da Universidade de Brasília.

Desde que um funcionário dos Arquivos Nacionais, agora aposentado, descreveu sua carreira como a de "um glorioso arquivista no período de trinta e cinco anos!"1, muitas mudanças ocorreram nessa profissão. Mais do que nunca, os arquivistas exigem maior reconhecimento profissional. Um aspecto desta campanha é a crescente preocupação com a teoria arquivística. Proliferam teorias em todas as disciplinas acadêmicas: os físicos inventam a relação de dispersão e teorias unificadas de grande calibre; os linguistas estudam a análise e as teorias da sintaxe; economistas usam modelos de estoque para construir teorias de renda e flutuação; epistemólogos debatem uma vastidão de teorias conflitantes sobre conhecimento e percepção. Muitos arquivistas acreditam que deve haver um corpo teórico semelhante, estritamente fundamentado em tais propostas obscuras como os cinco níveis de arranjo e o conceito de evidência.

Frank G. Burke propôs uma divisão de arquivistas em "teóricos" e "clínicos". Ele sustenta que o grupo antigo, instalado na academia, deve dedicar seu tempo a desenvolver uma "nova filosofia dos arquivos", "princípios", "dogma", "conceitos transcendentes" e "explicações paradigmáticas". ${ }^{2}$ Buscando acentuar a validade intelectual da teoria arquivística, Burke e outros invocam nomes de grandes filósofos e literários como Georg Hegel, Ludwig Wittgenstein, Marshall McLuhan e Kurt Vonnegut; Jr. ${ }^{3}$ Richard Berner foi ainda mais longe com

\footnotetext{
1 Conversa do autor com Philip R. Ward, Sr., Poder Judiciário, Fiscal e Social, Arquivo Nacional, Washington, D.C., abril de 1986, sobre um dos ex-colegas de Ward.

2 Burke, Frank G. The Future Course of Archival Theory in the United States, American Archivist 44 (Winter 1981), p. 45-6.

${ }^{3}$ Burke. Future Course of Archival Theory. p. 45; Evans, Max. Authority Control: An Alternative to the Record Group Concept, American Archivist 49 (Summer 1986): p. 260; Ham, F. Gerald. The Archival Edge, American Archivist 38 (January 1975): p.13; Cook, Terry. From Information to Knowledge: An Intellectual Paradigm for Archives, Archivaria 19 (Winter 1984-85): p. 46.
} 
o subterfúgio poético ao comparar a persistência de uma tradição particular de pensamento arquivístico com o crepúsculo de verão no ártico." ${ }^{4}$

O campo, no entanto, não pode ser tão fértil como Burke sugere. Há duas categorias que se passam por teoria arquivística: uma categoria é arquivística, mas não é teórica, e lida com a prática; em como fazer, com aspectos importantes do trabalho arquivístico. Envolve a codificação de procedimentos de controle de documentos existentes e ajustes para desenvolver métodos mais eficientes; esta é a responsabilidade dos clínicos em arquivos. 0 outro é teórico, mas não arquivístico, e está preocupado com a historiografia. Demanda um conhecimento do contexto histórico e do valor dos documentos, não sendo uma tarefa para arquivistas enquanto arquivistas, mas para arquivistas enquanto historiadores ou, pelo menos, enquanto estudantes de História. Tudo isso torna o território muito restrito para o arquivista teórico em sua qualidade de arquivista teórico. Além do mais, os apelos para o desenvolvimento de um corpo teórico da Arquivologia derivam mais de uma necessidade emocional decorrente de maior aceitação profissional do que uma necessidade objetiva por mais teoria arquivística.

Na categoria "prática" em teoria arquivística há muitos trabalhos clássicos na profissão (Muller, Feith, e Fruin; Schellenberg; e Holmes), bem como nos esforços recentes de Berner, Teoria e Prática Arquivística nos Estados Unidos (Archival Theory and Practice in the United States). ${ }^{5}$ Esses trabalhos estabeleceram os procedimentos que os arquivistas devem observar no momento de gerir os arquivos e coleções de manuscritos: os valores, níveis de arranjo, item de descrição, descrição colaborativa, esquema de classificação, inventário cronológico, e assim por diante. Por vezes, tais estudos podem encobrir as mentes mais entorpecidas por minúcias, à medida que eles mergulham exaustivamente em pontos detalhados das tabelas, notas de classificação, instrumentos de pesquisa, arranjo alfabético versus arranjo cronológico, e tamanho e configuração de páginas de folhas soltas que ofereçam uma alternativa para fichas $^{6}$ de catálogo ${ }^{7}$. Isso certamente é teoria, mas apenas no sentido vocacional, assim como

\footnotetext{
${ }^{4}$ Berner, Richard C. Archival Theory and Practice in the United States: A Historical Analysis. Seattle: University of Washington Press, 1984, p.73.

${ }^{5}$ Como exemplo, consultar: Muller, Samuel; Feith, J. A.; Fruin R., Manual for the Arrangement and Description of Archives, trans. Arthur H. Leavitt, New York: H.W. Wilson, 1940; Holmes, Oliver Wendell. "Archival Arrangement-Five Different Operations at Five Different Levels, in A Modern Archives Reader: Basic Readings on Archival Theory and Practice, ed. Maygene Daniels and Timothy Walch. Washington National Archives, 1984. Schellenberg, T.R. Modern Archives: Principles and Techniques. Chicago: University of Chicago Press, 1956.

${ }^{6}$ Por exemplo, ver Schellenberg. Modern Archives, p. 55-59 e 74-78; e Schellenberg. The Management of Archives. New York: Columbia University Press, 1965, passim. Para uma revisão sobre a teoria de "porcas e parafusos", ver Pinkett, Harold T. American Archival Theory: The State of the Art. American Archivist 44 (Summer 1981), p. 217-22.
} 
manuais de instrução ou livros de anotação que em qualquer serviço clerical ou ocupacional devem ser chamados de teoria.

Esse tipo de teoria pode ser exagerada e, às vezes, tende a expressar o óbvio em termos demasiadamente complicados. Dissecações acadêmicas nos níveis de arranjo e de análises detalhadas relativas ao simples ato de um arquivista responder à demanda de um usuário sobre documentos são dois exemplos de como escritores na área de arquivo lutam para conceituar o mundano. ${ }^{8}$ Além do mais, esses debates são menos significativos que uma troca de sugestões referentes a caminhos mais efetivos para redigir o escopo de notas, preparar inventários, organizar cartas recebidas ou lidar com itens volumosos. Eles estão longe dos emocionantes movimentos dialéticos que Burke imagina.

No seu nível mais elevado, a categoria "como fazer?", inerente à teoria arquivística, fornece aos arquivistas marcos importantes tais como proveniência, ordem original, conceito de fundo e Registraturprinzip. Indubitavelmente, esses conceitos têm um elemento maior de teoria per se, por exemplo, que teoria de indexação, uma vez que um deles é baseado em princípios verdadeiramente abstratos. No entanto, em última instância, os conceitos têm a ver com organização, classificação e recuperação, e, portanto, são ferramentas em grande parte, práticas, e não algum tipo de talismã cultural como alguns afirmam. Mesmo que o turbulento debate sobre controle de autoridade versus fundo seja importante, representa simplesmente uma etapa a mais no processo prático e contínuo de gestão arquivística e discussão sobre quais ferramentas devem ser utilizadas.

De acordo com Berner, o objetivo de "como fazer" na literatura deve ser o desenvolvimento de um sistema geral que sirva como modelo teórico para orientar a prática. ${ }^{9}$ $\mathrm{Na}$ realidade, isso consistiria sobretudo em fórmulas específicas direcionadas a problemas isolados. Os escritos de Berner, por exemplo, documentam suas descobertas e estudos nos arquivos da University of Washington. Obviamente, eles são apropriados a um repositório em

\footnotetext{
7 Segundo o Glossário da Sociedade Americana de Arquivistas, catalog cards corresponderia a "descrições de materiais, com cada entrada em uma ficha separada (ou cartões), organizados sistematicamente para facilitar o acesso." CATALOG CARD (n.). Society of American Archivist. Glossary. Acesso: 05 de novembro de 2018. Disponível: https://www2.archivists.org/glossary/terms/c/cardcatalog.

${ }^{8}$ Holmes. Archival Arrangement. p.162-80; Chalou, George. Reference, in A Modern Archives Reader, $p$. 257-63; e Chalou, George. "Reference Service", folheto distribuído no curso de treinamento do Arquivo Nacional, em setembro de 1985. No material impresso, Chalou é tão analítico ao examinar a função de referência que abstrai "documentos", "usuários" e "funcionários do arquivo" como os elementos separados que compõem o "ponto de convergência". "Ponto de convergência" é outra maneira de dizer "responder a uma pergunta".

${ }^{9}$ Berner. Archival Theory. p. 75.
} 
particular, e indubitavelmente, podem ser adotados, com revisões, por repositórios de tamanho ou propriedades similares, mas não como leis universais.

Claramente é indispensável que arquivistas sejam capazes de trabalhar com modelos e diretrizes. Caso contrário, eles seriam impelidos a "reiventar a roda" ao elaborar novos trabalhos. Do mesmo modo, é essencial que essas diretrizes sejam revisadas, periodicamente, a fim de refletirem as mudanças na tecnologia e para comunicarem as descobertas dos melhores caminhos de atuação em diversas funções. Teorias de avaliação imaginadas por Theodoro Schellenberg e Philip Brooks, por exemplo, não podem guiar o avaliador de documentos legíveis por máquina, a menos que sejam alteradas pelas diretrizes específicas de Charles Dollar sobre a avaliação de documentos eletrônicos. ${ }^{10}$

No entanto, essa literatura é orientada exclusivamente para o que F. Gerald Ham chama de "aspectos técnicos"11 da profissão. Mesmo quando se explica o "porquê" de uma forma particular de arranjo e avaliação ser recomendada, ainda assim, concentra-se mais na metodologia que no conteúdo, reduzindo-se a explicação a uma codificação técnica. É o tipo de teoria, 'tais como a relevância mundana de arranjo e descrição, técnicas de microfilmagem ou laminação, e a estrutura ramificada dos arquivos organizacionais', que Burke expressamente exclui do campo a ser considerado pelos arquivistas teóricos. Os teóricos deveriam, argumentou ele, "discutir questões maiores..."12

A segunda linha de teoria arquivística discute grandes problemas, mas esses problemas pertencem à Arquivologia? Por um lado, esse tipo de teoria pode ser visto como historiografia aplicada. Concentra-se no conteúdo e contexto dos documentos, e não em sua estrutura ou nos processos que os controla.

No Limite Arquivístico (The Archival Edge), Ham denuncia o hábito de documentar apenas a história das elites e apela para que os arquivistas preencham os espaços vazios dentro do arquivo histórico. ${ }^{13} \mathrm{O}$ artigo de Ham busca voltar-se para o futuro, mas é claramente o produto de uma tradição historiográfica que já é um pouco trivial. No entanto, seu ponto é bem elaborado: arquivistas devem tomar muitas decisões como historiadores profissionais, não como meros custodiadores. Eles devem estar atentos para o saber histórico, a fim de antecipar futuros interesses de pesquisa e até mesmo para neutralizar as tendências historiográficas deletérias por meio de políticas criativas de aquisições. Assim como Ham,

\footnotetext{
${ }^{10}$ Ver Dollar, Charles M. Appraising Machine-Readable Records; in A Modern Archives Reader. p. 71-79.

${ }^{11}$ Ham. Archival Edge. p. 7.

12 Burke. Future Course of Archival Theory. p. 42.

${ }^{13}$ Ham. Archival Edge. p.5-7 e 9; Ham, F. Gerald. Archival Strategies for the Post-Custodial Age, American Archivist 44 (Summer 1981), p. 207.
} 
Burke invoca a historiografia em suas ponderações sobre a teoria arquivística quando ele argumenta as necessidades de uma compreensão da história cultural por detrás de qualquer conjunto de documentos. ${ }^{14}$

De forma paradoxal, é nesse ponto que a teoria arquivística se torna irrelevante. Proveniência, hierarquias, os cinco níveis de arranjo, catalogação, controle de autoridade e até mesmo métodos de implementação de decisões arquivísticas, baseados nas tendências historiográficas, tornam-se, na melhor das hipóteses, tangenciais. O conhecimento do saber histórico e o conhecimento do conteúdo de um determinado fundo tornam-se componentes essenciais para realizar decisões com base em informações pertinentes e profissionais sobre avaliação, descrição e referência. Ler e reter cada palavra já escrita na teoria arquivística ou nos procedimentos arquivísticos não fornecerá ao arquivista qualquer assistência para determinar o significado histórico de um conjunto de documentos ou para tratar perguntas de um pesquisador.

O fato é que uma preocupação excessiva com leituras puramente voltadas para questões arquivísticas pode ser um claro obstáculo. Um funcionário de órgão federal tem criticado o Arquivo Nacional por esse órgão não nomear um avaliador de documentos; esse tipo de profissional poderia complementar as credenciais dos arquivistas com um conhecimento adequado tanto da história do órgão, quanto do período durante o qual os arquivos foram produzidos e seus documentos criados..$^{15} \mathrm{Um}$ caso como esse indica que um historiador, sem treinamento nos arquivos, poderia executar decisões muito mais justificáveis e profissionais do que um arquivista com uma experiência inadequada em História ou com conhecimento insuficiente sobre os arquivos.

Observações semelhantes podem ser feitas com respeito a outros aspectos do trabalho arquivístico. A preservação é, nitidamente, uma preocupação na Arquivologia e conservadores devem estar familiarizados com a teoria arquivística. No entanto, o profissionalismo que o conservador deve exibir e a criatividade que ele deve empregar não estão relacionados aos arquivos, mas, sim, centrados na química, física e outras disciplinas científicas. Enquanto isso, especialistas em arquivos automatizados utilizam procedimentos arquivísticos apenas para tomarem decisões com base em seu conhecimento técnico. E o que conta mais para arquivistas que lidam com decisões sobre acesso é conhecer a lei.

A teoria arquivística, então, é reduzida a um pouco mais que uma forma de implementar decisões, que são feitas de acordo com o conhecimento histórico ou outro. Nós

\footnotetext{
${ }^{14}$ Burke. Future Course of Archival Theory. p. 42-44.

${ }^{15}$ Conversa do autor em meados de fevereiro de 1986.
} 
economizamos o que é historicamente valioso: lá. Essa é a teoria. A partir daí o assunto se torna estudar os documentos e estudar a História, mas isso não tem a ver com a Arquivologia. Arquivologia é pós-historiográfica. Se os argumentos de Ham e Burke são válidos, a implicação seria o arquivista ter que estudar História, estar familiarizado com a literatura dessa área, e talvez mesmo trabalhar como profissional, pesquisador histórico, bem antes mesmo de iniciar operando na Arquivologia. As decisões baseadas na História e as operações baseadas na Arquivologia, enquanto inextricavelmente ligadas, são inevitavelmente separadas. Elas são tão distintas uma da outra quanto a inspiração do poeta é diferente das canetas e do papel que a capturam.

Desse modo é apropriado repetir a pergunta de Burke: "Há algo para ser teorizado?"16 Na realidade, um aspecto da teoria arquivística é clínico e especifica as operações frequentemente de controle mecânico que devem ser seguidas no tratamento dos fundos. 0 outro aspecto da teoria arquivística diz respeito à resposta arquivística à historiografia, a qual arrasta completamente o arquivista, em última análise, para fora da Arquivologia e o posiciona no âmbito da historiografia. $\mathrm{O}$ que resta para ocupar a mente dos arquivistas teóricos?

Três áreas vêm à mente. A primeira é uma extensão do esforço historiográfico na teoria arquivística e envolve a tradução da historiografia para termos arquivísticos. A segunda, e talvez a mais convincente das três, envolve a avaliação da validade do esforço historiográfico na teoria arquivística e leva a questões relativas a razões para a existência da profissão. 0 terceiro é concernente à avaliação e reavaliação de diversos "pormenores" que frequentemente são deixados de lado no trabalho arquivístico. No entanto, um olhar mais minucioso para esses assuntos mostra que o desgaste do território dos arquivistas teóricos é mais profundo.

A primeira questão da teoria é essencialmente a de sintetizar a história com as necessidades arquivísticas. Por exemplo, as afirmações de Ham de que os arquivistas devem fornecer documentos históricos mais precisos, exigem um corolário: que sejam criados métodos para isso. As propostas de Ham são mais ambiciosas. Afirma que o arquivista deveria deixar de ser "um catavento movido pelas mudanças dos ventos da historiografia" e repete o apelo de Sam Bass Warner para que o arquivista se torne "um repórter histórico para o seu próprio tempo", reunindo as informações necessárias para completar o arquivo histórico. Ham continua a defender os arquivos especializados e o inter-relacionamento entre os arquivos. ${ }^{17}$

Enquanto Ham espera que os arquivistas sejam menos sujeitos à "moda do mercado acadêmico", seu artigo, escrito em meados da década de 1970, e repleto de entusiasmo pelos

\footnotetext{
${ }^{16}$ Burke. Future Course of Archival Theory. p. 42.

${ }^{17}$ Ham. Archival Edge. p. 7-12; Ham. Archival Strategies. p. 207, 211-212.
} 
arquivos urbanos e pelo projeto histórico Eugene McCarthy, reflete nitidamente as tendências historiográficas de sua época. ${ }^{18}$ Além disso, ao sugerir que os arquivistas participem, ativamente, como "repórteres" na criação dos documentos históricos, ele pede que esses profissionais se tornem fotógrafos, economistas, estatísticos e demógrafos, ao invés de arquivistas. Mesmo concordando com essas afirmações de Ham, as implicações têm a ver com os procedimentos de controle, e não com a teoria arquivística. As políticas de aquisições criativas, as redes de arquivos e os arquivos especializados, proclamadas por Ham, podem estar em uma escala muito maior do que os procedimentos de marcação ou métodos de indexação; mas ainda são as porcas e parafusos que Ham acredita estar evitando. Tomar as ideias de Ham e convertê-las em conteúdo arquivístico significa buscar práticas mais eficientes

Tal como Ham, Burke lida com o problema da fusão da História com a Arquivologia. Ele é sensível aos debates na profissão da História em relação à subjetividade e ao relativismo. Burke argumenta que os arquivistas teóricos podem tentar elaborar teorias que ajudem a profissão a "elevar-se acima de seu próprio ambiente social e intelectual" para fornecer uma verdade intocada aos historiadores do futuro. ${ }^{19}$ Lester Cappon acusa Burke de confundir a verdade arquivística com a verdade histórica e elogiar a "imparcialidade e a autenticidade" dos documentos. ${ }^{20}$ Gregg Kimball apoia a posição de Burke, ao mostrar como até mesmo as teorias arquivísticas, supostamente imparciais, e sobre as quais Cappon baseava seus argumentos a respeito da verdade arquivística, foram coloridas por seus meios intelectuais. ${ }^{21}$

Há mérito nos argumentos dos três autores, entretanto, em um sentido mais amplo, Burke, Cappon e Kimball estão a favor de um ponto discutível. É claro que a verdade arquivística é maculada pelas mesmas influências temporais e culturais que distorcem a verdade histórica; toda ideia é moldada pelo seu tempo, não importando quão sincero seu autor se esforce pela objetividade. Não é razoável esperar que a comunidade arquivística possa formular teorias que Ihe permitam transcender suas amarras culturais. Aliás, ao tentar fazê-lo, corre-se o risco de distorcer ainda mais a verdade. Os historiadores do futuro poderão avaliar o grau de parcialidade dos arquivistas contemporâneos, por meio do seu conhecimento da cultura atual. Se os arquivistas se esforçarem muito para consagrar sua ideia de verdade

\footnotetext{
18 Ham, Archival Edge. p. 8, 10, 11. Embora não seja acrítico ao Projeto McCarthy e dos arquivos urbanos, Ham parece defender o desenvolvimento de arquivos especializados quando complementados por redes de arquivos. A escolha de Ham por tais exemplos indica uma familiaridade com as tendências historiográficas contemporâneas, sem mostrar a previsão que ele parece instar os arquivistas a exibir.

${ }^{19}$ Burke. Future Course of Archival Theory. p.43.

${ }^{20}$ Cappon, Lester J. What, Then, Is There to Theorize About? American Archivist 45. Winter 1982. p. 2325; Kimball, Gregg D. The Burke-Cappon Debate: Some Further Criticisms and Considerations for Archival Theory. American Archivist 48. Fall 1985. p. 372-373.

${ }^{21}$ Kimball. Burke-Cappon Debate. p. 372-375.
} 
objetiva, não apenas continuarão a ser aprisionados por seu ambiente cultural mas, também, privarão os historiadores do futuro do método para entender seus preconceitos. O melhor que os arquivistas podem fazer é manter-se a par dos estudos históricos atuais e fazer os julgamentos mais fundamentados possíveis, baseando-se em cada caso particular. Tentar criar uma teoria de arquivos atemporais, se desejar, é tão fútil quanto contraproducente.

Mais fundamental seria questionar se a História deveria estar ligada à Arquivologia. Os apelos de Ham e Burke representam um afastamento teórico radical que contraria as teorias de Hillary Jenkinson, segundo as quais o arquivista não é um historiador e o dever do arquivista não é para com a História, e sim para com os "seus arquivos". ${ }^{22}$ Em sua resposta a Burke, Cappon ecoa Jenkinson, advertindo que "uma aliança dos arquivos com a História" ameaçaria a independência da disciplina arquivística. ${ }^{23}$

Tem-se, genuinamente, uma disputa teórica de grande magnitude, que impulsiona questões mais básicas e abrangentes sobre quem são os arquivistas, o porquê da existência de instituições arquivísticas, e o porquê esse tema ser, apenas recentemente, parte de uma série de divertidos artigos na revista canadense Archivaria. ${ }^{24}$ No entanto, em certo sentido, o arquivista teórico que enfrenta esse dilema está entre "a cruz e a espada". ${ }^{25}$ Se o arquivista teórico se posiciona ao lado da escola jenkinsoniana, ou alguma variação dessa, então a posição do intelectual muda imediatamente da categoria da prática para a categoria da teoria e da preocupação com a técnica. ${ }^{26}$ Se os teóricos concluem a favor de Ham e Burke, a historiografia assume o controle, ou, em outras palavras, até mesmo essa questão vital da teoria arquivística passa a oferecer oportunidades limitadas para um debate. É provável que, com uma leve variação, o argumento sobreviverá eternamente. Mas poucas questões novas serão produzidas, e uma vez que qualquer teórico esteja satisfeito com algum tipo de conclusão, o aspecto da teoria arquivística desaparece; a questão então se torna de historiografia ou de metodologia.

Tudo isso deixa apenas algumas questões isoladas a serem tratadas sob a rubrica de teoria. Essas preocupações mostram que os arquivistas fazem seu trabalho com as seguintes

\footnotetext{
${ }^{22}$ Cappon. What, Then, Is There to Theorize About? p. 23.

23 Ibid., 25.

${ }^{24}$ Cook. From Information to Knowledge. p. 28-49; Taylor, Hugh. Information Ecology and the Archives of the 1980s. Archivaria 18 (Summer 1984). p. 25-37; Bolotenko, George. Archivists and Historians: Keepers of the Well. Archivaria 16 (Summer 1983). p. 5-25; Dunae, Patrick A. et al., Special Feature: The Debate Over History and Archives. Archivaria 17 (Winter 1983-84). p. 286-308.

${ }^{25}$ Nota da tradutora: o termo Scylla de Charibdis vem da mitologia grega e significa uma escolha entre dois infernos. Acesso em 05 de outubro de 2018. Disponível em: https://en.wikipedia.org/wiki/Between_Scylla_and_Charybdis

${ }^{26}$ Um exemplo de preocupação com a tecnologia em detrimento do conteúdo. Vaisey, Bob Taylor. Archivist- Historians Ignore Information Revolution. Archivaria 17 (Winter 1983-84). p. 305-308.
} 
premissas: quanto mais antigo um documento, maior o valor de retenção; arquivos volumosos têm uma importância maior que arquivos pouco volumosos; a proveniência é um método superior de recuperação para indexação de conteúdo; os arquivos centrais são mais importantes que os arquivos setoriais; os documentos do diretor são mais importantes que os do diretor-assistente; e assim por diante. ${ }^{27}$

Conversar sobre esses tópicos, até para testá-los na prática, não é contraproducente para os arquivistas; pode ser, sob alguns aspectos, até agradável. Mas não vejo a menor necessidade de que acadêmicos da Arquivologia desenvolvam dogma sobre esses pontos com a precisão e o comprometimento que, digamos, Marx e Engels demonstraram ao escrever Das Kapital. Não é preciso ser um gênio para adivinhar as razões por trás de tais suposições, nem para descobrir suas desvantagens. É óbvio o motivo pelo qual documentos mais antigos normalmente teriam maior valor informativo; entretanto, limita-se à obviedade que, em muitos casos, documentos mais antigos teriam valor apenas como artefatos. Os argumentos que favorecem a teoria do arquivo volumoso não são de todo ilusórios, nem tampouco o fato de os arquivos volumosos serem frequentemente volumosos em trivialidades.

É apropriado que os arquivistas trabalhem a partir de conjuntos de premissas e igualmente apropriado que questionem essas premissas. Parece provável, entretanto, que tais perguntas possam ser elaboradas e competentemente respondidas por qualquer arquivista, sem a intervenção de teóricos de tempo integral. Não são apenas as perguntas suficientemente fáceis que não exigem uma abordagem seminarista de Burke, mas elas também são de tal natureza que nenhuma resposta dogmática seria suficiente. Em alguns casos, a teoria dos arquivos volumosos seria apropriada; em outros casos, não. A proveniência pode ser um método superior em geral, mas alguns repositórios podem ser perfeitamente justificados ao adotar a indexação de conteúdo, dependendo do volume e da natureza de suas propriedades e da frequência de solicitações de referência. Pode ser benéfico para os arquivistas tornarem-se familiarizados com as teorias sociológicas relativas às organizações, mas as relações de poder dentro de uma organização e os documentos produzidos por uma organização variam de tal forma que a teoria nunca substitui um conhecimento firme da organização e de seus documentos. A questão final, de qualquer maneira, não se configuraria

\footnotetext{
${ }^{27}$ A proveniência versus a indexação de conteúdo é considerada completa, com intrigantes fluxogramas quase tão impressionantes quanto as primeiras representações de Linus Pauling de moléculas de proteína, em Lytle, Richard H. Intellectual Access to Archives. American Archivist 43 . Winter 1980 and Spring 1980. p. 64-75, 191-206. Questões relativas à teoria organizacional e ao processo de tomada de decisão em órgãos corporativos são levantadas em Burke. Future Course of Archival Theory. p. 43.
} 
em uma teoria arquivística, mas em um dos documentos, seu conteúdo, seu significado e seu repositório.

Assim como muitos afirmam que a Teologia revela mais sobre a sociedade e a $\mathrm{P}$ Psicologia do que sobre a divindade, a teoria arquivística pode desvelar mais sobre os arquivistas do que sobre o trabalho arquivístico. Com a exceção daqueles que trabalham em instituições maiores e exclusivamente arquivísticas, os arquivistas permanecem, muitas vezes, isolados uns dos outros e cercados por profissionais corporativos ou governamentais que tendem a considerá-los funcionários de arquivo. Em algumas instituições, à medida que os procedimentos se tornam mais rígidos e os cronogramas de produção mais restritos, os arquivistas podem deparar-se com o fato de o seu trabalho ter sido reduzido ao nível de um técnico. Além disso, à medida que aumenta a importância dos documentos automatizados, os arquivistas devem prestar cada vez mais atenção aos especialistas em computação em matérias de preservação, avaliação e gestão de documentos. ${ }^{28}$ Outros profissionais também violam o domínio dos arquivistas e, às vezes, entram em conflito com sua missão: especialistas em relações públicas, educadores, bibliotecários e curadores, por exemplo. Finalmente, com uma alta porcentagem de arquivistas do gênero feminino, a profissão, como um todo, pode estar sujeita a um tipo de discriminação e condescendência nos campos profissionais, há muito, direcionada às mulheres por parte dos administradores do gênero masculino. ${ }^{29}$ Diante de situação tão perturbadora, não é de se surpreender que alguns grupos na profissão vejam o diploma como procedimento que trará aos arquivistas maior reconhecimento, melhores salários e mais independência. Da mesma forma, o desenvolvimento da teoria arquivística pode parecer atraente como opção para atingir os mesmos objetivos que, embora possa aumentar sua respeitabilidade, representa uma armadilha acadêmica para a profissão.

Melhor regulamentação talvez colocasse menos ênfase nas aparências e maior atenção nas questões básicas. A pergunta de Burke poderia ser reformulada na seguinte forma: "O que há, então, para os arquivistas pensarem?" A resposta é que há muito o que pensar, mas pouco disso tem a ver com teoria. A literatura sobre aspectos práticos ou metodológicos da arquivística, embora frequentemente árida e técnica, pode ser intelectualmente exigente e é sempre essencial.

\footnotetext{
${ }^{28}$ Clubb, Jerome M. Archival Implications of Technological and Social Change in Archivists and MachineReadable Records, ed. Carolyn L. Geda, Erik W. Austin, and Francis X. Blouin, Jr. (Ann Arbor: 1980). p. 238-239.

${ }^{29}$ Nota da tradutora: de acordo com o autor, esse motivo nos levaria a entender a razão de alguns profissionais se sentirem inseguros e a origem de conflitos entre esses profissionais.
} 
Para não ser confundida com teorias gerais e amplas, a literatura técnica engloba principalmente soluções temporárias, desenvolvidas por clínicos para enfrentar problemas imediatos, e que somente oferecem orientação e sugestões a outros clínicos com tarefas semelhantes. É provável que uma porcentagem muito pequena dessa literatura seria universalmente valiosa, mas, como um todo, ela poderia encontrar audiência em alguma parte da profissão. O fluxo interminável de artigos e manuais sobre porcas e parafusos atesta a necessidade de desenvolver, implementar e divulgar melhores procedimentos. Há também uma ética de arquivar, não se tratando, conforme mencionado anteriormente, de leis ou princípios, mas de observações gentis, como as "Reflexões de um arquivista" de Jenkinson, que ajudam os profissionais a meditarem sobre o seu "chamado". Finalmente, e talvez mais importante, há as informações contidas nos documentos, a história e a historiografia que formam o contexto intelectual dessas informações, a natureza das organizações e os indivíduos que produziram os documentos. Somente tornando-se especialistas em assuntos nessas áreas é que os arquivistas realmente se tornam algo mais que arquivistas e podem fazer julgamentos fundamentados sobre recolhimento, preservação e serviços de manutenção de documentos. Com tanta coisa para se fazer, essa teoria arquivística pretensiosa configura um desvio bastante supérfluo e pouco promissor.

Cappon está correto em resistir a teorizações excessivamente ambiciosas e quasehistoriográficas sobre procedimentos arquivísticos. Mas ele erra ao tentar manter um rígido delineamento entre o arquivista e o historiador e ao parecer restringir os arquivistas a um caminho reto e estreito, definido por nomes como Galbraith, Leland e outros, em seus manuais e reflexões. Burke e Ham fazem muito sentido ao pedirem aos arquivistas para abrirem suas mentes e aprofundarem seus pensamentos. Mas Burke superestima o potencial de uma Arquivologia pura como uma busca acadêmica que vale a pena e convida ao ceticismo, ao associar contendas arquivísticas aos grandes pensamentos da civilização ocidental. Convidando a um ceticismo ainda maior, Ham apresenta esquemas grandiosos com o intuito de enviar os arquivistas a campo a fim de capturar as informações, que a seu ver não tem mais ninguém suficientemente esperto para capturar.

Acima de tudo, deve ser lembrado que a Arquivologia, por si só, é uma ocupação razoavelmente direta e simples; não é uma ciência liberal, e não deve ser confundida com os tesouros culturais e históricos mantidos pelos repositórios arquivísticos. Para ser efetivo, o conhecimento que os arquivistas devem ter pode ser facilmente resumido: esses profissionais precisam conhecer procedimentos e tecnologia; precisam conhecer a ética da profissão e o que se espera deles; precisam conhecer a História; e, especialmente, precisam saber sobre 
seus arquivos. Tudo o mais é desnecessário ou se encaixará bem sem a mediação de um sacerdócio de teóricos.

Grandes coisas estão acontecendo no mundo das ideias. Poemas estão sendo escritos, sinfonias estão sendo compostas, doenças estão sendo controladas, eras históricas estão sendo sondadas e dilemas econômicos estão sendo analisados. Em meio a tudo isso, é de extrema tolice intelectual se confundir com fantasmas tão absurdos quanto paradigmas arquivísticos, elos simbióticos de mídia e mensagem, filosofia de $m y l a r^{30}$ e outras armações que alguns arquivistas iriam empurrando para frente como credenciais para se sentar à mesa dos adultos.

30 Nota da tradutora: Mylar é uma marca registrada de propriedade da Dupont Tejjin Films para uma família específica de produtos de chapas de plástico feitos a partir da resina polietileno tereftalato (PET). Os termos genéricos verdadeiros para este material são filmes de poliéster ou folhas de plástico. Wikipédia. Acesso em: 5 de novembro de 2018. Disponível: https://pt.wikipedia.org/wiki/Mylar. 